\title{
Avaliação medicinal e nutricional de três espécies de Plantas Alimentícias Não convencionais (PANCs): Uma revisão de literatura
}

Medicinal and nutritional evaluation of three species of Unconventional Food Plants (UFPs): A literature review

Evaluación medicinal y nutricional de tres espécies de plantas alimentícias no convencionales (PANC): Revisión de la literatura

\author{
Mariana Sobreira Bezerra \\ ORCID: https://orcid.org/0000-0003-2868-2974 \\ Universidade Federal de Santa Maria, Brasil \\ E-mail: marisbezerra1@gmail.com \\ Felipe Somavilla Binotto \\ ORCID: https://orcid.org/0000-0002-0295-863X \\ Universidade Federal de Santa Maria, Brasil \\ E-mail: somavillafelipe31@gmail.com \\ Neila Silvia Pereira dos Santos Richard \\ ORCID: https://orcid.org/0000-0001-6610-5567 \\ Universidade Federal de Santa Maria, Brasil \\ E-mail: neilarichardsprof@gmail.com \\ Aline Sobreira Bezerra \\ ORCID: https://orcid.org/0000-0003-1370-9564 \\ Universidade Federal de Santa Maria, Brasil \\ E-mail: alinecelo@hotmail.com \\ Flávia Kolling Marquezan \\ ORCID: https://orcid.org/0000-0003-1505-2447 \\ Universidade Federal de Santa Maria, Brasil \\ E-mail:flaviamarquezan@gmail.com \\ Patricia Kolling Marquezan \\ ORCID: https://orcid.org/0000-0001-5061-6039 \\ Universidade Federal de Santa Maria, Brasil \\ E-mail: patimarquezan@ hotmail.com
}

\begin{abstract}
Resumo
Nos últimos anos, o aumento da busca por alternativas medicinais e nutricionais para introdução no campo da saúde das pessoas ocasionou a utilização de plantas no cotidiano da população. Consequentemente, diversas pesquisas almejavam avaliar o potencial uso de tais plantas e seus benefícios para a saúde. Portanto, o objetivo do estudo é realizar uma revisão de literatura sobre a potencial utilização medicinal e nutricional de três espécies presentes na região Sul do Brasil, sendo elas Rumex crispus, Conyza bonariensis e Taraxacum officinale. Foram realizadas pesquisas nas bases de dados PubMed, EMBASE, Biblioteca Virtual de Saúde (BVS) e Repositório digital da Universidade Federal de Santa Maria, utilizando os descritores anteriormente selecionados das plataformas MeSh e DeCs. As buscas foram realizadas no período de dezembro de 2020. O critério de inclusão utilizado englobava artigos dos últimos 20 anos, porém foram excluídas revisões de literatura. Após as buscas foram selecionados 27 artigos para compor a revisão de literatura. As plantas são ricas em diferentes fitoquímicos, que garantem às espécies diferentes usos em potencial, como antioxidantes, anti-inflamatórios, anti-diabéticos, antimicrobianos e anticancerígenos. Além disso, seus usos na alimentação são abrangentes, sendo encontrados em saladas, molhos, geleias ou chás. A maioria das plantas apresentou atividade citotóxica contra células tumorais, porém a toxicidade contra células saudáveis não foi observada pelos estudos. Portanto, observa-se o potencial medicinal e nutricional das espécies analisadas, sendo necessários mais estudos para a sua elucidação na prática clínica.
\end{abstract}

Palavras-chave: Agentes anti-infecciosos; Conyza; Rumex; Taraxacum.

\begin{abstract}
In the last years, the increase in the search for medicinal and nutritional alternatives for introduction into the field of people's health has led to the use of plants in the daily lives of the population. Consequently, several studies aimed to evaluate the potential use of such plants and their health benefits. Therefore, the aim of the study is to conduct a literature review on the potential medicinal and nutritional use of three species present in the southern region of Brazil, namely Rumex crispus, Conyza bonariensis and Taraxacum officinale. Research was carried out in the
\end{abstract}


PubMed, EMBASE, Virtual Health Library (VHL) and Digital Repository databases at the Federal University of Santa Maria, using the previously selected descriptors from the MeSh and DeCs platforms. The searches were carried out in the period of December 2020. The inclusion criteria used included articles from the last 20 years, but literature reviews were excluded. After the searches 27 articles were selected to compose the literature review. Plants are rich in different phytochemicals, which guarantee species with different potential uses, such as antioxidants, antiinflammatories, anti-diabetics, antimicrobials and anticancer agents. In addition, its uses in food are wide, being found in salads, sauces, jellies or teas. Most plants showed cytotoxic activity against tumor cells, but toxicity against healthy cells was not observed in the studies. Therefore, the medicinal and nutritional potential of the analyzed species is observed, and further studies are needed to elucidate it in clinical practice.

Keywords: Anti-infective agents; Conyza; Rumex; Taraxacum.

\section{Resumen}

En los últimos años, el incremento en la búsqueda de alternativas medicinales y nutricionales para su introducción en el campo de la salud de las personas ha llevado al uso de plantas en la vida diaria de la población. En consecuencia, varios estudios tuvieron como objetivo evaluar el uso potencial de tales plantas y sus beneficios para la salud. Por tanto, el objetivo del estudio es realizar una revisión de la literatura sobre el potencial uso medicinal y nutricional de tres especies presentes en la región sur de Brasil, a saber, Rumex crispus, Conyza bonariensis y Taraxacum officinale. La investigación se realizó en las bases de datos PubMed, EMBASE, Virtual Health Library (BVS) y Repositorio Digital de la Universidad Federal de Santa María, utilizando los descriptores previamente seleccionados de las plataformas MeSh y DeCs. Las búsquedas se realizaron en el período de diciembre de 2020. Los criterios de inclusión utilizados incluyeron artículos de los últimos 20 años, pero se excluyeron las revisiones de la literatura. Después de las búsquedas se seleccionaron 27 artículos para componer la revisión de la literatura. Las plantas son ricas en diferentes fitoquímicos, que garantizan especies con diferentes usos potenciales, como antioxidantes, antiinflamatorios, antidiabéticos, antimicrobianos y agentes anticancerígenos. Además, sus usos en la alimentación son amplios, encontrándose en ensaladas, salsas, jaleas o tés. La mayoría de las plantas mostraron actividad citotóxica contra las células tumorales, pero en los estudios no se observó toxicidad contra las células sanas. Por tanto, se observa el potencial medicinal y nutricional de las especies analizadas, siendo necesarios más estudios para dilucidarlo en la práctica clínica.

Palabras clave: Agente anti-infecciosos; Conyza; Rumex; Taraxacum.

\section{Introdução}

O estudo de plantas com fins medicinais e nutricionais tem aumentando vertiginosamente durante os anos. Áreas como a fitoterapia e as Plantas Alimentícias Não Convencionais (PANCs) são cada vez mais valorizadas dentro do meio científico e social, principalmente devido às vantagens de utilização de plantas no cotidiano, que contam com uma grande biodisponibilidade, facilidade de aquisição pela população, efeitos tóxicos baixos ou nulos e, por fim, resultados promissores com relação a outras terapias já existentes (Francisco, 2010).

As Plantas Alimentícias Não Convencionais podem ser definidas como espécies que possuem partes comestíveis, incluindo-se sua utilização como tempero, corante, infusão, entre outros (Kinupp; Barros, 2007). O Brasil ganha grande destaque com relação à área das PANCs, principalmente devido à sua grande variedade biológica. Apesar disso, não se observa o consumo em larga escala de espécies que fujam ao cotidiano, sendo utilizadas levando em consideração as diferentes culturas de cada região e sua influência na dieta de sua população (Tuler; Peixoto; Silva, 2019).

$\mathrm{Na}$ região Sul do país, observa-se uma grande quantidade de plantas com potencial alimentício em diferentes preparações (Kinupp; Barros, 2007), e esse dado relevante também aponta para uma possível utilização de tais espécies na medicina tradicional. Três espécies ganham destaque por esses aspectos, sendo elas Rumex crispus (Labaça-crespa), Conyza bonariensis (Buva) e Taraxacum officinale (Dente de leão). Apesar de serem de famílias e gêneros distintos, a literatura atual aponta não só sua utilização com fins medicinais, mas também na dieta objetivando melhorar a saúde física e nutricional, principalmente devido a sua rica composição em fitoquímicos.

Diante disso, o objetivo do presente estudo foi investigar os usos tradicionais na medicina e na nutrição de três espécies encontradas na região Sul, sendo elas Rumex crispus, Conyza bonariensis e Taraxacum officinale. 


\section{Metodologia}

A revisão de literatura seguiu os preceitos do estudo descritivo de caráter qualitativo por meio de uma pesquisa bibliográfica em livros e artigos científicos. O método qualitativo foi utilizado pelos pesquisadores pois possibilita a interpretação e emissão de suas opiniões sobre o que é estudado (Pereira et al., 2018). Foram realizadas buscas distintas, sendo incluídos artigos que abordassem as plantas pesquisadas (Rumex crispus, Conyza bonariensis e Taraxacum officinale) nos últimos 20 anos. Foram excluídos estudos que não contemplassem a temática do presente trabalho. As buscas eletrônicas foram realizadas nas bases de dados PubMed, EMBASE, BVS e Repositório digital da Universidade Federal de Santa Maria para artigos publicados até agosto de 2020.

Utilizou-se os descritores previamente selecionados a partir das plataformas MeSH, DeCS e Emtree, sendo adaptados para cada base de dados escolhida. As buscas foram realizadas por dois pesquisadores no período de Novembro a Dezembro de 2020. As termos buscados, bem como suas combinações por meio dos operadores booleanos "AND" e "OR" estão descritos na Quadro 1 juntamente com os resultados e o número de estudos selecionados.

Quadro 1. Combinação dos descritores nas bases de dados e resultados.

\begin{tabular}{|c|c|c|c|c|}
\hline PLANTA & BASES DE DADOS & DESCRITORES & $\begin{array}{l}\text { RESUL } \\
\text { TADOS }\end{array}$ & $\begin{array}{c}\text { SELECIO } \\
\text { NADOS }\end{array}$ \\
\hline Conyza bonariensis & Embase & $\begin{array}{l}\text { 'Conyza bonariensis'/exp OR 'conyza bonariensis' OR } \\
\text { buva OR 'voadeira' OR 'rabo de foguete' OR 'arranha } \\
\text { gato' }\end{array}$ & 72 & 6 \\
\hline Conyza bonariensis & PubMed & $\begin{array}{llcr}\text { (Conyzas OR Asthmaweed } & \text { OR Horseweed) } & \text { AND } \\
\text { (Ethnopharmacology } & \text { OR } & \text { Phytotherapy } & \text { OR } \\
\text { Ethnomedicine } & \text { OR } & \text { Traditional Medicine } & \text { OR } \\
\text { Phytochemical OR Dietary } & \text { Phytochemical OR } & \text { Edible } \\
\text { Plant OR diet) } & & & \end{array}$ & 39 & 3 \\
\hline Conyza bonariensis & $\begin{array}{l}\text { Repositório digital da } \\
\text { Universidade Federal de } \\
\text { Santa Maria }\end{array}$ & "Conyza bonariensis" & 51 & 1 \\
\hline Conyza bonariensis & BVS & $\begin{array}{llr}\text { (Conyzas OR Asthmaweed OR Horseweed) } & \text { AND } \\
\text { (Ethnopharmacology OR O Phytotherapy } & \text { OR } \\
\text { Ethnomedicine OR Traditional Medicine } & \text { OR } \\
\text { Phytochemical OR Dietary Phytochemical OR Edible } \\
\text { Plant OR diet) }\end{array}$ & 115 & 7 \\
\hline Rumex crispus & Embase & 'Rumex crispus'/exp OR 'curled dock' OR 'rumex crispus' & 121 & 3 \\
\hline Rumex crispus & PubMed & $\begin{array}{l}\text { (Rumex crispus OR Yellow Dock OR Dock, Yellow) } \\
\text { AND (Ethnopharmacology OR Phytotherapy OR } \\
\text { Ethnomedicine OR Traditional Medicine OR } \\
\text { Phytochemical OR Dietary Phytochemical OR Edible } \\
\text { Plant OR diet) }\end{array}$ & 173 & 5 \\
\hline Rumex crispus & BVS & $\begin{array}{l}\text { (Rumex crispus OR Yellow Dock OR Dock, Yellow) } \\
\text { AND (Ethnopharmacology OR Phytotherapy OR } \\
\text { Ethnomedicine OR Traditional Medicine OR } \\
\text { Phytochemical OR Dietary Phytochemical OR Edible } \\
\text { Plant OR diet) }\end{array}$ & 290 & 12 \\
\hline Taraxacum officinale & Embase & $\begin{array}{l}\text { ('Dandelion'/exp OR 'Taraxacum officinale'/exp) } \\
\text { ('phytotherapy'/exp OR 'ethnopharmacology'/exp OR } \\
\text { 'traditional medicine'/exp OR 'phytochemistry'/exp OR } \\
\text { 'diet'/exp OR 'edible plant'/exp) }\end{array}$ & 318 & 1 \\
\hline
\end{tabular}




\begin{tabular}{|c|c|c|c|c|}
\hline Taraxacum officinale & PubMed & $\begin{array}{lllr}\text { (Dandelion OR } & \text { Taraxacum } & \text { officinale) } & \text { AND } \\
\text { (Ethnopharmacology } & \text { OR } & \text { Phytotherapy } & \text { OR } \\
\text { Ethnomedicine OR } & \text { Traditional Medicine } & \text { OR } \\
\text { Phytochemical } & \text { OR Dietary Phytochemical OR } & \text { Edible } \\
\text { Plant OR diet) } & & & \end{array}$ & 218 & 8 \\
\hline Taraxacum officinale & BVS & $\begin{array}{lccr}\text { (Dandelion OR } & \text { Taraxacum officinale) } & \text { AND } \\
\text { (Ethnopharmacology } & \text { OR } & \text { Phytotherapy } & \text { OR } \\
\text { Ethnomedicine OR } & \text { Traditional Medicine } & \text { OR } \\
\text { Phytochemical OR Dietary Phytochemical OR } & \text { Edible } \\
\text { Plant OR diet) } & & & \end{array}$ & 5.585 & 11 \\
\hline
\end{tabular}

Fonte: Autores (2021).

Após a vasta busca pela literatura, os artigos foram selecionados por título e resumo, eliminando as duplicatas posteriormente e realizando a leitura crítica dos estudos considerados elegíveis. Foram excluídos artigos pelos critérios de exclusão (fuga do tema e duplicatas) até chegar aos artigos incluídos na revisão de literatura. Do total de estudos encontrados foram selecionados 27 artigos científicos que contemplavam a temática. A seleção seguindo critérios foi fundamental para a melhor confiabilidade e poder de generalização das conclusões desse estudo.

\section{Resultados e Discussão}

\subsection{Conyza bonariensis}

\section{Especificações da planta e locais onde se encontra}

A espécie Conyza bonariensis, também conhecida popularmente no Brasil como buva, voadeira, margaridinha-docampo, rabo-de-foguete, arnicão, entre outros, pode ser identificada também pelos nomes Erigeron linifolium Willd., Erigeron bonariensis L., Erigeron crispus Pourret e Flaxleaf fleabane fora do país (Barbora et al., 2005; Mabrouk et al., 2011; Schechtel et al., 2019). A planta pertence à família Asteraceae e ao gênero Conyza, que possui 17 espécies entre ervas perenes, bienais e anuais, além de possuir usos medicinais conhecidos em casos para tratamento de malária e feridas, além de ação antiinflamatória, analgésica, antiviral e antidiarreica (Mabrouk et al., 2011; Araujo et al., 2013).

Essa erva daninha perene, nativa da América do Sul, pode ser encontrada em diferentes locais do mundo, como na América do Norte, Europa, regiões montanhosas e em países de clima temperado, tropical e subtropical (Mabrouk et al., 2011; Araujo et al., 2013; Bukhari et al., 2013; Thabit et al., 2015; Schechtel et al., 2019).

\section{Composição fitoquímica}

Segundo os autores, os diferentes extratos da planta podem indicar diferentes concentrações de cada composto químico. No estudo de De Paula et al. (2018), o extrato metanólico de C. bonariensis demonstrou em testes in vitro uma composição fitoquímica rica em flavonoides, taninos, esteróides livres, antraquinonas reduzidas e cumarinas, enquanto no extrato etanólico da planta foi observada abundância em polifenólicos, flavonoides, taninos e antocianinas (Thabit et al., 2015).

O extrato aquoso do estudo de Favila (2006) mostrou-se rico em mucilagens, saponinas, antocianinas, ácidos orgânicos voláteis e monossacarídeos (oses), enquanto o extrato hidroalcoólico possuía compostos diferentes, como esteróides triterpenos, ácidos orgânicos, flavonoides, fenóis e cardiotônicos. O extrato hidroalcoólico da erva daninha de Schechtel et al. (2019) entra em consenso com Favila (2006) por também apresentar-se abundante em diferentes ácidos, sendo alguns deles o ácido cafeico, elágico, rosmarínico e gálico.

O fracionamento dos extratos também foi analisado segundo o perfil cromatográfico, sendo as frações de acetato de etila e butanol as mais ricas em ácido gálico e fenólicos (Favila, 2006). 
O óleo essencial da planta analisado pelos métodos de cromatografia gasosa (GC) acoplada e espectrometria de massa mostrou ser composto em mais da metade por componentes do tipo sesquiterpênicos (Araujo et al., 2013). Barbosa et al. (2005), em sua análise, utilizou todas as partes da planta (flores, folhas, caule e raízes) e observou-se que cada parte da planta possuía compostos mais prevalente, sendo nas flores e no caule o diterpeno manool e a carvona, nas folhas o limoneno e nas raízes o éster matricária. A maioria dos resultados entra em consenso com a análise de Mabrouk et al. (2011), que observou nas flores o trans- $\alpha$-bergamoteno, nas folhas o óxido de cariofileno, no caule a geranilacetona e nas raízes o éster matricária. As diferenças entre os estudos podem ser explicadas na diferença da porcentagem dos compostos nas quatro estações do ano, sendo mais altas no verão, e nas diferentes regiões do mundo de onde as plantas foram utilizadas (Mabrouk et al., 2011).

\section{Usos medicinais}

De acordo com a literatura, a planta é vastamente utilizada na medicina tradicional para tratamento de problemas gastrointestinais, tosse, dor de cabeça, dor de dente, cistite, nefrite, leishmaniose cutânea, varíola dolorosa, gota e úlceras estomacais, além de ser conhecido também como laxante, hemostático, anti-helmíntico, diurético, antibacteriano, antiinflamatório, vermífugo, antisséptico, antiespasmódico, hepatoprotetor e anti-hemorroidal (Barbosa et al., 2005; Favila, 2006; Mabrouk et al., 2011; Araujo et al., 2013; Bukhari et al., 2013; Thabit et al., 2015; Bukhari et al., 2018; De Paula et al., 2018; Potbhare et al., 2019).

Bukhari et al. (2013), ao estudar a farmacologia da planta relacionada ao tratamento de problemas gastrointestinais, observou que a fração de butanol possui constituintes espasmogênicos, que garantem uma ação contra constipação, agindo semelhantemente à acetilcolina, um neurotransmissor regulador dos movimentos peristálticos do intestino. Além disso, as frações de acetato de etila e hexano, por possuírem constituintes espasmolíticos, conferem à planta uma ação antiespasmódica e antidiarreica pelo fato de agirem de maneira semelhante aos antagonistas dos canais de cálcio que, em sua normalidade, permitem a contração celular.

Além disso, em seu outro estudo sobre o efeito analgésico e anti-inflamatório da planta in vivo, Bukhari et al. (2018) concluíram que as frações de n-hexano, clorofórmio, acetato de etila, butanol e água suprimiram as respostas nociceptoras, permitindo ação analgésica. Ademais, as frações de n-hexano e butanol demonstraram ótimos resultados sobre a inibição do edema induzido de carragenina em roedores do estudo, comprovando sua boa ação anti-inflamatória.

A ação antioxidante da $C$. bonariensis tem sido foco de estudos devido à sua rica composição em fenólicos e flavonoides, que são um indicativo para bons resultados antioxidantes (Thabit et al., 2015). Os extratos etanólico, hidroalcoólico e metanólico mostraram efeitos promissores (Thabit et al., 2015; Potbhare et al., 2019; Schechtel et al., 2019), e as frações de acetato de etila e butanol, por serem ricos em fenólicos, demonstraram ótima atividade antioxidante (Favila, 2006).

Em relação à atividade antimicrobiana, De Paula et al. (2018) observou pelo método de disco-difusão que as bactérias mais afetadas pelo extrato metanólico foram E. feacalis (folha), S. pyogenes (folha), S. flexneri (raiz) e os fungos C. kruzei (folha), C. parapsilosis (folha e raiz), C. glabrata (folha) e C. albicans (raiz). Thabit et al. (2015), na análise do extrato etanólico da planta, concluiu que houve melhor ação antimicrobiana sobre bactérias gram positivas, como $S$. aureus e $S$. pyogenes. Outros microrganismos foram apontados pela literatura como sendo sensíveis à planta, como L. monocytogenes, E. coli, B. cereus, P. aeruginosa, S. typhimurium e S. enteritidis (Schechtel et al., 2019).

O óleo essencial da planta, segundo Araujo et al. (2013) demonstrou atividade antimicrobiana contra B. cereus e ação moderada contra $C$. albicans e S. epidermis. A confecção de nanopartículas contendo as plantas Phyllanthus reticulatus e Conyza bonariensis obteve resultados satisfatórios contra os microrganismos S. aureus, K. pneumoniae e E. coli (Potbhare et al., 2019). Os resultados de Favila (2006) com os óleos voláteis da raiz de C. bonariensis mostraram-se efetivos somente 
contra as bactérias gram-negativas $K$. pneumoniae e $E$. coli e os fungos $C$. albicans e $S$. cerevisiae, principalmente devido aos compostos acetilênicos da planta. $O$ extrato bruto e suas frações não demonstraram ação antimicrobiana nesse mesmo estudo.

\section{Usos nutricionais}

Schechtel et al. (2019) apontam para a utilização tradicional da C. bonariensis na alimentação, sendo comum a preparação de saladas cruas e também como molho para salada devido à sua rica composição. Ademais, Bukhari et al. (2013) citam em seu estudo a preparação de refrigerantes a partir da infusão das pétalas da planta.

Schechtel e colaboradores (2019), em se tratando da composição nutricional da planta, observaram que a $C$. bonariensis possui grande porcentagem de proteínas, lipídeos e carboidratos, sendo uma parcela desses de fibras dietéticas.

\section{Citotoxicidade e toxicidade}

A citotoxicidade da planta foi demonstrada por diversos autores in vitro e in vivo, sendo demonstrada atividade contra células tumorais (Araujo et al., 2013), células cancerígenas (Schechtel et al., 2019) e contra Artemia salina, que pode indicar ação antitumoral ou inseticida (Favila, 2006).

Com relação à toxicidade, nenhum dos autores observou indícios de toxicidade in vivo (Favila, 2006; Bukhari et al., 2018; De Paula et al., 2018). No estudo de Favila (2006), o autor salienta que a toxicidade está diretamente relacionada à dose administrada, bem como a via administrada. Com relação à dose máxima não letal, De Paula et al. (2018) estipula doses seguras até os valores de $5000 \mathrm{mg} / \mathrm{kg}$, enquanto Burhari et al. (2018) define a dose máxima não fatal de $2 \mathrm{mg} \mathrm{kg}^{-1}$.

\subsection{Rumex crispus}

\section{Especificações da planta e locais onde se encontra}

A espécie Rumex crispus, também conhecida internacionalmente como "curly dock" ou "yellow dock", é uma planta perene com a característica marcante de possuir folhas onduladas ou crespas. Tal planta pertence à família Polygonaceae e ao gênero Rumex, que possui cerca de 14 espécies vastamente conhecidas por seus bons resultados na fabricação de cataplasma em casos de furúnculo, além de serem utilizadas no tratamento de disenteria, enterite e ascaridíase (Idris; Wintola; Afolayan, 2017; Orbán-Gyapai et al., 2017; Minh et al., 2019; Cebović et al., 2020).

A planta é normalmente encontrada em ambientes úmidos, como pântanos, ou em locais de solo ácido. Além disso, pode crescer em locais desertos, perto de estradas e locais gramados (Ćebović et al., 2020; Eom, Kim; Kim, 2020).

\section{Composição fitoquímica}

De acordo com os artigos, a espécie é rica em flavonoides, com destaque à presença dos compostos bioativos crisofanol e fisciona em suas raízes, polifenólicos, antraquinonas, como a emodina, proantocianidinas, flavonol, saponinas e alcaloides (Idris; Wintola; Afolayan, 2017; Minh et al., 2019; Cebović et al., 2020; Eom, Kim; Kim, 2020).

Em um estudo do extrato etanólico das raízes da planta e suas frações de n-hexano, diclorometano, acetato de etila, nbutanol e água, observou-se que a fração de acetato de etila possuía a composição mais rica em polifenólicos, enquanto a porcentagem de flavonoides e antraquinonas era maior na fração de diclorometano (Eom, Kim; Kim, 2020). Idris; Wintola; Afolayan (2017), ao analisarem os extratos metanólico, etanólico, em acetona e aquoso das raízes e folhas, também observaram maior prevalência de fenólicos e proantocianidinas nas raízes, em especial no extrato em acetona. Esse mesmo extrato, sendo, porém, das folhas, foi considerado o mais rico em flavonoides e flavonol, e todos os extratos das folhas mostraram níveis mais elevados de saponinas e alcaloides do que as raízes. 


\section{Usos medicinais}

Na medicina tradicional, a espécie é utilizada como anti-inflamatório, tônico, purificador de sangue, antimicrobiano, digestivo, laxante, infecções dermatológicas, anti-helmíntico, antipirético, tratamento de feridas e também como tratamento adjuvante no tratamento de câncer. Além disso, é usado em doenças da vesícula biliar, do trato respiratório superior, do trato gastrointestinal, de pele e vasculares (Idris; Wintola; Afolayan, 2017; Idris; Wintola; Afolayan, 2019; Minh et al., 2019).

As partes individuais da planta também são utilizadas em diferentes ocasiões. Suas frutas são consideradas boas no tratamento de problemas estomacais, como disenteria. Além disso, suas raízes e folhas possuem efeito laxante, adstringente para hemorróidas e espasmolítico (Minh et al., 2019; Ćebović et al., 2020).

Diversos autores buscaram avaliar a atividade antioxidante da R. crispus. Amidi et al. (2012), em seu estudo com o extrato metanólico das folhas da espécie observou ótima atividade antioxidante por meio da voltametria cíclica, porém Idris; Wintola; Afolayan (2017) concluem que as raízes possuem maior atividade antioxidante que as folhas. O extrato e a fração em acetato de etila tiveram bons resultados, sendo esses resultados prováveis pela presença de crisofanol, que mostrou-se um composto bioativo com alto poder antioxidante (Minh et al., 2019; Eom, Kim; Kim, 2020). O extrato aquoso da planta das folhas, sementes e frutas demonstrou potencial antioxidante e de poder de eliminação de radicais livres (Ćebović et al., 2020).

A atividade antimicrobiana também foi avaliada em diversos estudos, sendo observadas as raízes, erva, folhas e flores. A fração aquosa de erva e raízes apresentou inibição de S. epidermidis, S. aureus e S. aureus resistente à meticilina (MRSA), enquanto a fração aquosa da erva foi efetiva contra B. subtilis e M. catarrhalis. A fração de clorofórmio proveniente das raízes inibiu as duas bactérias S. pyogenes e S. pneumoniae (Orbán-Gyapai et al., 2017). No estudo de Idris; Wintola; Afolayan (2019), o extrato em acetona das raízes produziu os melhores resultados, sendo inibidos K. pneumoniae, P. aeruginosa, E. coli, V. cholera, B. subtilis, S. aureus, S. pyogenes e B. cereus. Além disso, os extratos metanólico e etanólico das raízes também apresentaram alta capacidade inibitória sobre diversos microrganismos, incluindo o parasita Trypanosoma brucei brucei, sendo observados melhores resultados do extrato etanólico sobre esse. O extrato hidroalcoólico também apresentou atividade antifúngica para C. albicans e C. glabrata (Veres et al., 2012; Bineshian et al., 2019)

Em seu estudo sobre a capacidade anti-gota, anti-radical e anti-diabética da planta, Minh et al. (2019) observaram que o composto ativo crisofanol, proveniente das raízes da planta, apresentou ótima inibição da xantina oxidase, presente na gota. Além disso, o crisofanol e a fisciona inibiram duas enzimas relacionadas com a diabetes do tipo $2, \alpha$-Amilase e $\alpha$-Glucosidase, demonstrando seu potencial anti-diabético.

Eom, Kim e Kim (2020) avaliaram a ação anti-inflamatória e anticancerígena das frações de n-hexano, diclorometano, acetato de etila, n-butanol e água. A partir da avaliação da citotoxicidade em macrófagos leucêmicos de camundongos, concluiu-se que a fração de acetato de etila foi a mais efetiva frente à atividade anti-inflamatória, inibindo a secreção de citocinas pró-inflamatórias. Além disso, as frações de hexano e diclorometano demonstraram atividade inibitória no rescimento de células cancerosas de hepatoma humano, comprovando seu potencial anticancerígeno.

\section{Usos nutricionais}

Segundo Idris; Wintola; Afolayan (2019), as folhas da R. crispus são ricas em compostos nutricionais, como minerais, proteínas, fibras, magnésio, potássio, sódio, fósforo, cobre e manganês, enquanto sua raiz é abundante em gorduras, carboidratos, cálcio, zinco e ferro. As vitaminas em maior quantidade na planta são o retinol (vitamina A), ácido ascórbico (vitamina C) e tocoferol (vitamina E).

A literatura aponta para a utilização das folhas novas da planta na alimentação, sobretudo em porções de verduras cozidas, sopas e saladas cruas (Yildirim; Mavi; Kara, 2001; Idris; Wintola; Afolayan, 2019; Minh et al., 2019). Por ser rica em minerais, proteínas, fibras e vitaminas, seu consumo pode ser benéfico nutricionalmente, porém, em sua composição estão 
presentes certos anti-nutrientes, como o ácido fítico e o oxalato, que podem afetar a digestão de certos minerais, proteínas e lipídeos, além de saúde, como no caso de pedras nos rins em decorrência do oxalato, devendo, assim ser consumido em quantidades moderadas a fim de reduzir efeitos nocivos (Vasas; Orbán-Gyapai; Hohmann,2015; Idris; Wintola; Afolayan, 2017).

\section{Citotoxicidade e toxicidade}

A citotoxicidade da planta in vitro frente a células de carcinoma cervical humano, adenocarcinoma do cólon, adenocarcinoma da mama (Idris; Wintola; Afolayan, 2019; Ćebović et al., 2020) e células cancerosas de hepatoma humano (Eom, Kim; Kim, 2020) foi observada. O extrato aquoso de frutas demonstrou atividade antitumoral eficiente e seletiva, tendo como principal mecanismo de indução de morte celular a necrose (Ćebović et al., 2020). Além disso, os extratos etanólico e em acetona das raízes também foram efetivos contra as células de carcinoma cervical humano (Idris; Wintola; Afolayan, 2019). Por fim, Eom, Kim e Kim (2020) concluíram que as frações de hexano e diclorometano inibiram o crescimento de células cancerosas de hepatoma humano, sendo o mecanismo da fração de diclorometano a partir da indução de apoptose.

A planta não apresentou sinais de toxicidade em células saudáveis no estudo de Ćebović et al. (2020), mas Idris; Wintola; Afolayan (2019) apontam para os valores duas vezes mais elevados de toxicidade dos extratos provenientes das raízes da planta do que das folhas, sendo os mais tóxicos os extratos metanólico e em acetona e o menos tóxico o extrato aquoso da folha.

\subsection{Taraxacum officinale}

\section{Especificações da planta e locais onde se encontra}

A espécie Taraxacum officinale, comumente conhecida no Brasil como dente-de-leão, em outros locais do mundo pode ser denominada dandelion, Herba Taraxaci,ou Taraxacum herba. Essa planta pode ser encontrada em diversas regiões temperadas, sendo considerada nativa da Ásia. (Clare; Conroy; Spelman, 2009; Díaz et al., 2018)

Sua família, Asteraceae, é conhecida por possuir espécies comestíveis em saladas ou em misturas vegetais, enquanto seu gênero, Taraxacum, é muito utilizado na medicina popular tradicional da Europa, Ásia e Américas por seu efeito diurético e por auxiliar em casos de distúrbios urinários e renais. (Clare; Conroy; Spelman, 2009; Petropoulos et al., 2019).

\section{Composição fitoquímica}

O dente-de-leão, segundo diversos autores, é rico em tocoferóis, ácidos orgânicos, compostos fenólicos, como a luteolin-7-O-rutinoside e os ésteres do ácido cafeico, ácidos hidroxicinâmicos, como o ácido chicórico, flavonoides (rutina e catequina), ácido gálico, resveratrol, ácido vanílico, ácido sinápico, e taraxastarol. (López-García et al., 2013; Wang et al., 2017; Petropoulos et al., 2019; Majewski et al., 2020; Majewski et al., 2021).

Segundo Días et al. (2018), o extrato em hexano da planta possui diversos compostos dos grupos dos triterpenóides, terpenos, além de ftalato de dietila, ácidos graxos, aldeídos, cetonas e álcoois. Os compostos em maior porcentagem são o acetato de lupeol, betulina, lupeol, entre outros. Já o extrato em acetato etílico é rico principalmente em compostos dos grupos dos triterpenóides, terpenos, ftalato de dietila, ácidos graxos e derivados, aldeídos, cetonas, álcoois e alguns compostos não identificados. O acetato de lupeol, fitol, betulina e outros compostos fitoquímicos são observados em grandes quantidades em tal extrato.

Além disso, o mesmo autor observou que as folhas da planta possuem vários ácidos graxos, como o ácido palmítico, ácido alfalinolênico e ácido linoleico (Díaz et al., 2018). 


\section{Usos medicinais}

A espécie é muito utilizada em diversos locais do mundo para fins medicinais, terapêuticos, e dietéticos, auxiliando em doenças cardiovasculares, câncer, estresse oxidativo, diabetes, doenças inflamatórias, pneumonia, distúrbios renais e de vesícula biliar. Além disso, ela é útil como antisséptico, antifúngico, antiespasmódico, antimicrobiano, antifúngico, diurético, antirreumático, antidiabético e antioxidante (Lópxez-garcía et al., 2013; Wang et al., 2017; Díaz et al., 2018; Petropoulos et al., 2019; Sekhon-Loodu; Rupasinghe, 2019; Majewski et al., 2020).

A análise antimicrobiana da planta concluiu que as bactérias Bacillus cereus, Staphylococcus aureus, Escherichia coli. Observou-se também que o extrato em hexano inibiu as bactérias Gram-positivas de forma mais efetiva (Días et al., 2018; Petropoulos et al., 2019). Lópes-Garcia et al. (2013), no entanto, não identificou inibição microbiana em seu estudo in vitro com as bactérias E. coli e $S$. aureus, sendo, portanto, necessários mais estudos sobre a temática.

A atividade anti-diabética do dente-de-leão também foi avaliada por um autor. Os extratos aquoso e etanólico no estudo de Sekhon-loodu; Rupasinghe (2019) inibiram significativamente a formação dos produtos finais de glicação avançada, sendo um indício de seu potencial uso para pacientes hiperglicêmicos com diabetes do tipo 2.

Além disso, a planta apresentou potencial contra a obesidade induzida em ratos. Segundo Majewski et al. (2020) e Majewski et al. (2021), os níveis de HDL, triglicerídeos, colesteróis totais, índice de combinação de lipoproteínas e índice aterogênico do plasma foram diminuídos, demonstrando efeitos benéficos in vivo. De acordo com outro estudo in vitro que objetivava analisar a atividade adipogênica da $T$. officinale, as gotículas lipídicas observadas pelos autores se mostraram pequenas e houve baixa adipogênese (Sekhon-loodu; Rupasinghe, 2019).

Clare, Conroy e Spelman (2009) investigaram a ação diurética do extrato hidroetanólico das folhas de dente-de-leão. Na primeira dose administrada em humanos, houve aumento da frequência de micção, e na segunda dose observou-se aumento da proporção de excreção urinária, mostrando-se promissor como diurético em humanos.

O dente-de-leão foi avaliado segundo sua atividade antioxidante. Majewski et al. (2021) observou que um xarope feito a partir da planta foi eficaz no aumento da atividade da enzima superóxido dismutase, que participa do processo antioxidante. Além disso, houve a redução da atividade do malondialdeído, que tem a capacidade de diminuir ou desacelerar a peroxidação lipídica relacionada à oxidação. Outro estudo demonstrou que houve alta atividade de eliminação de radicais DPPH pela planta (Sekhon-Loodu; Rupasinghe, 2019), e outro estudo demonstrou um efeito protetor no plasma sanguíneo, principalmente devido aos resultados positivos frente aos biomarcadores do estresse oxidativo (Majewski et al., 2020), sendo então uma espécie promissora para atividade antioxidante

O efeito anti-inflamatório da T. officinale foi observado por Wang et al. (2017) em seu estudo in vivo. A partir da indução da formação de diferentes edemas em ratos, os autores concluíram que os edemas de orelha e pata dos camundongos diminuíram em função da dose de planta administrada, enquanto também houve diminuição da permeabilidade vascular e inibição da formação de granuloma induzido por pelotas de algodão. Isso demonstra que a espécie possui ação antiinflamatória, segundo o estudo, dependente da dose.

\section{Usos nutricionais}

Segundo Petropoulos et al. (2019), a planta pode ser utilizada em dietas, como em saladas, por possuir um potencial alimentício devido à sua rica composição fitoquímica (Clare; Conroy; Spelman, 2009). Abbet et al. (2014) apontam que tal planta já é utilizada em larga escala na alimentação de certos locais, como na Suíça, principalmente nas formas de chá, geléia, em preparações como vegetais cozidos, compota e lanche cru. Seus brotos são encontrados em saladas, sopas ou misturados com ovos e pão frito. Majewski et al. (2021) também observa que o xarope de dente de leão pode ser utilizado para produção de marmeladas, chás, licores, vinho, cervejas, sobremesas e doces. 


\section{Citotoxicidade e toxicidade}

Os dados dos artigos não foram claros quanto a citotoxicidade da planta, sendo necessários mais estudos sobre tal temática.

Nos estudos in vivo, não se observou modificação do peso, da digestão, dos batimentos cardíacos, da pressão sanguínea e nem da massa interna do coração, fígado, rins e baço dos camundongos. Os autores concluíram que não houve efeitos maléficos nas concentrações aplicadas, sendo isso de suma importância no estudo da toxicidade da planta. (Majewski et al., 2020; Majewski et al., 2021).

Além de tais estudos, López-García et al. (2013) observou uma mínima interferência do dente-de-leão na viabilidade celular dos queratinócitos não tumorais, sendo, portanto, classificado como de baixa toxicidade.

\section{Considerações Finais}

Segundo os estudos avaliados, as plantas Conyza bonariensis, Rumex crispus e Taraxacum officinale possuem ações medicinais e nutricionais promissoras principalmente devido às suas extensas e ricas composições fitoquímicas. Além disso, não houve relatos de toxicidade pelos autores, sendo isso relevante para futuras pesquisas.

São necessários mais estudos, porém, sobre a extensão das atividades das plantas, bem como de seus efeitos no organismo humano, para que haja a aplicabilidade clínica das mesmas e de seu aproveitamento integral, não sendo vistas somente como ervas daninhas ou invasivas, mas como fonte nutricional e medicinal para a população.

\section{Referências}

Abbet, C., Mayor, R., Roguet, D., Spichiger, R., Hamburger, M., \& Potterat, O. (2014) Ethnobotanical survey on wild alpine food plants in Lower and Central Valais (Switzerland). Journal of ethnopharmacology, 151(1):624-634.

Amidi, S., Mojab, F., Moghaddam, A.B., Tabib, K., \& Kobarfard, F. (2012). A simple electrochemical method for the rapid estimation of antioxidant potentials of some selected medicinal plants. Iranian Journal of Pharmaceutic Research. 11(1):117-21.

Araujo, L., Moujir, L.M., Rojas, J., Rojas, L., Carmona, J., \& Rondón, M. (2013) Chemical composition and biological activity of Conyza bonariensis essential oil collected in Mérida, Venezuela. Natural Product Communication. 8(8):1175-8.

Barbosa, L. C. A., Paula V. F., Azevedo, A. S., Silva, E. A. M, \& Nascimento E. A. (2015). Essential oil composition from some plant parts of Conyza bonariensis (L.) Cronquist. Flavor and Fragrance Journal 20(1); 39-41.

Bineshian, F., Bakhshandeh, N., Freidounian, M., \& Nazari, H. (2019).Anti-Candida and antioxidant activities of hydroalcohlic extract of Rumex obtusifolius leaves. Pakistan Journal of Pharmaceutical Science; 32(3): 919-926

Bukhari, I.A., Shah, A.J., Khan, R.A., Meo, S.A., Khan, A., \& Gilani, A.H. (2013). Gut modulator effects of Conyza bonariensis explain its traditional use in constipation and diarrhea. European Review of Medical and Pharmacological Science. 17(4):552-8.

Bukhari, I. A. (2018). Peripheral analgesic and anti-inflammatory activities of the methanolic extracts of Conyza bonariensis and its fractions in rodents models. International Journal of Pharmacology. 14(1):144-150.

Ćebović, T., Jakovljevic, D.,Maksimović, Z. A., \& Simin, D. C. S. (2020). Antioxidant and cytotoxic activities of curly dock (Rumex crispus L., Polygonaceae) fruit extract. Vojnosanitetski pregled. 77(3)308-316.

Clare, B. A., Conroy, R. S., \& Spelman, K. (2009). The diuretic effect in human subjects of an extract of Taraxacum officinale folium over a single day. The Journal of Alternative and Complementary Medicine. 15(8): 929-934.

De Paula, C. C., \& Martins, D. T. O. (2018). Arunachalam K. Antimicrobial screening of medicinal plants popularly used in Mato Grosso for treating infections: Advances on the evaluation of Conyza bonariensis (L.) Cronquist in vitro and in vivo antibacterial activities. Pharmacognosy Journal, 10(6): 152$166 \mathrm{~s}$.

Díaz, K., Espinoza, L., Madrid, A., Pizarro, L., \& Chamy, R. (2018) Isolation and identification of compounds from bioactive extracts of Taraxacum officinale Weber ex FH Wigg.(Dandelion) as a potential source of antibacterial agents. Evidence-Based Complementary and Alternative Medicine, 2706417.

Eom, T., Kim, E., \& Kim, J. (2020). In vitro antioxidant, antiinflammation, and anticancer activities and anthraquinone content from Rumex crispus root extract and fractions. Antioxidants. 9(8): 726.

Favila, M. N. C. Estudo químico e biológico de conyza bonariensis (1.) cronquist (Asteraceae). 2006. Tese de Doutorado. Universidade Federal de Santa Maria. 
Francisco, K. S. F. (2010). Fitoterapia: Uma opção para o tratamento odontológico. Revista Saúde. 4(1): 18-24.

Idris, O. A., Wintola, O. A., \& Afolayan, A. J. (2019). Comparison of the proximate composition, vitamins (ascorbic acid, $\alpha$-tocopherol and retinol), antinutrients (phytate and oxalate) and the GC-MS analysis of the essential oil of the root and leaf of Rumex crispus L. Plants 8 (3):51.

Idris, O. A., Wintola, O. A., \& Afolayan, A. J. (2017). Phytochemical and antioxidant activities of Rumex crispus L. in treatment of gastrointestinal helminths in Eastern Cape Province, South Africa. Asian Pacific Journal of Tropical Biomedicine. 7(12):1071-1078

Idris, O. A., Wintola, O. A., \& Afolayan, A. J. (2019). Evaluation of the bioactivities of Rumex crispus L. leaves and root extracts using toxicity, antimicrobial, and antiparasitic assays. Evidence-Based Complementary and Alternative Medicine. 30:6825297.

Kinupp, V. F.; \& Barros, I. B .I. D. (2007). Riqueza de plantas alimentícias não-convencionais na região metropolitana de Porto Alegre, Rio Grande do Sul. Revista Brasileira de Biociências. 5(1): 63-65.

López-garcía, J. Polyphenolic extracts of edible flowers incorporated onto atelocollagen matrices and their effect on cell viability. Molecules. 8(11) 1343513445.

Majewski, M., Lis, B., Juśkiewicz, J., Ognik, K., Borkowska-Sztachańska, M., Jedrejek, D., Stochmal,A., \& Olas, B. (2020). Phenolic Fractions from Dandelion Leaves and Petals as Modulators of the Antioxidant Status and Lipid Profile in an In Vivo Study. Antioxidants (Basel). 3;9(2):131

Majewski, M., Lis, B., Juśkiewicz, J., Ognik, K., Jedrejek, D., Stochmal, A., \& Olas, B. (2021) The composition and vascular/antioxidant properties of Taraxacum officinale flower water syrup in a normal-fat diet using an obese rat model. Journal of Ethnopharmacol. 30;265:113393.

Minh, T. N., Van, T. M., Andriana, Y., Vinh, L. T., Hau, D. V., Duyen, D. H., \& Guzman-Gelani, C.(2019). Antioxidant, Xanthine Oxidase, $\alpha$-Amylase and $\alpha$ Glucosidase Inhibitory Activities of Bioactive Compounds from Rumex crispus L. Root. Molecules29; 24(21):3899

Orbán-Gyapai, O., Liktor-Busa, E., Kúsz N, Stefkó, D., Urbán, E., Hohmann. J., \& Vasas, A. (2017) Antibacterial screening of Rumex species native to the Carpathian Basin and bioactivity-guided isolation of compounds from Rumex aquaticus. Fitoterapia. 118:101-106

Pereira A. S. (2018). Metodologia da pesquisa científica. UFSM

Potbhare A. K., Chaudhary R. G., Chouke P. B., Yerpude S., Mondal A., Sonkusare V. N., Rai A. R., \& Juneja H. D. (2019). Phytosynthesis of nearly monodisperse $\mathrm{CuO}$ nanospheres using Phyllanthus reticulatus/Conyza bonariensis and its antioxidant/antibacterial assays. Material Science of Engineering C, Materials of Biological Application. 99:783-79.

Schechtel, S. L., de Matos, V. C. R., Santos, J. S., Cruz, T. M., Marques, M. B., Wen, M., Zhang, L., Furtado, M. M., Sant'Ana, A. S., Vieira do Carmo, M. A., Azevedo. L., Ribeiro, J. C. B., \& Granato, D. (2019). Flaxleaf Fleabane Leaves (Conyza bonariensis), A New Functional Nonconventional Edible Plant? Journal of Food Science. 84(12):3473-3482.

Sekhon-Loodu, S., \& Rupasinghe H. P. (2019). Evaluation of antioxidant, antidiabetic and antiobesity potential of selected traditional medicinal plants. Frontiers in nutrition. 6(1); 15-17.

Thabit, R. A., Cheng, X. R., Tang, X., Sun, J., Shi, Y. H., \& Le G. W. (2015). Antioxidant and antibacterial activities of extracts from Conyza bonariensis growing in Yemen. Pakistan Journal of Pharmaceutical Science. 28(1):129-34.

Tuler A. C., Peixoto A. L., \& Silva, N. C. B. (2020). Plantas alimentícias não convencionais (PANC) na comunidade rural de São José da Figueira, Durandé, Minas Gerais, Brasil. Rodriguésia. 70, e01142018.

Vasas, A., Orbán-Gyapai, O., \& Hohmann, J. (2015). The Genus Rumex: Review of traditional uses, phytochemistry and pharmacology. Journal of Ethnopharmacology, 4;(175):198-228

Veres, K., Csupor-Löffler, B., Lazarus, A., \& Hohmann, J. (2012). Antifungal activity and composition of essential oils of Conyza canadensis herbs and roots. The Scientific World Journal; 32(3): 919-920.

Wang, Y., Li, G.H., Liu, X.Y., Xu, L., Wang, S. S., \& Zhang X. M. (2016). In vivo anti-inflammatory effects of taraxasterol against animal models. African Journal of Traditional Complement Alternative Medicine.14(1):43-51. 